\title{
Neuroimaging findings and pathophysiology of dorsal spinal arachnoid webs: illustrative case
}

\author{
Nancy Pham, MD, ${ }^{1}$ Julius O. Ebinu, MD, PhD, ${ }^{2}$ Tejas Karnati, MD, ${ }^{2}$ and Lotfi Hacein-Bey, MD ${ }^{3}$ \\ ${ }^{1}$ Department of Radiology, University of California, Los Angeles, David Geffen School of Medicine, Los Angeles, California; and Departments of ${ }^{2}$ Neurosurgery and ${ }^{3}$ Radiology, \\ University of California, Davis, School of Medicine, Sacramento, California
}

\begin{abstract}
BACKGROUND Spinal arachnoid webs are uncommon and difficult to diagnose, especially because causative intradural transverse bands of arachnoid tissue are radiographically occult. Left untreated, arachnoid webs may cause progressive, debilitating, and permanent neurological dysfunction. Conversely, more than $90 \%$ of patients may experience rapid neurological recovery after resection, even with a prolonged duration of presenting symptoms. Indirect imaging signs such as spinal cord indentation and compression with cerebrospinal fluid (CSF) flow alteration provide crucial diagnostic clues that are critical in guiding appropriate management of such patients.

OBSERVATIONS The authors reported a patient with no significant medical history who presented with back pain, progressive lower extremity weakness, gait ataxia, and bowel and bladder incontinence. They discussed multimodality imaging for determining the presence of arachnoid webs, including magnetic resonance imaging, phase-contrast CSF flow study, computed tomography myelography, and intraoperative ultrasound. They also discussed the detailed anatomy of the spinal subarachnoid space and a plausible pathophysiological mechanism for dorsal arachnoid webs.
\end{abstract}

LESSONS The authors report on a patient who underwent comprehensive imaging evaluation detailing the arachnoid web and whose subsequent anatomical localization and surgical treatment resulted in a full neurological recovery.

https://thejns.org/doi/abs/10.3171/CASE2142

KEYWORDS arachnoid web; MRI; CT myelogram; ultrasound; surgery

Spinal arachnoid webs may cause progressive and potentially permanent morbidity. ${ }^{1-8}$ Although the pathogenesis of these lesions remains unclear, a study of the anatomy of the spinal subarachnoid spaces provides useful insight. Current neuroimaging commonly does not yield a direct diagnosis but provides useful indirect signs, primarily the "scalpel sign." who underwent comprehensive imaging and recovered fully after treatment. We also discuss spinal subarachnoid spaces and potential pathophysiological mechanisms.

\section{Illustrative Case}

A 66-year-old woman without significant medical history other than hypertension presented with recent exacerbation of chronic back pain, progressive lower extremity weakness, gait ataxia, and mild fecal and urinary incontinence. Magnetic resonance imaging (MRI) showed ventral displacement and dorsal indentation of the thoracic spinal cord at T4-5, upstream edema at T3-4, and no evidence of syringomyelia (Fig. 1A). Cerebrospinal fluid (CSF) flow MRI (Fig. 1B) showed robust biphasic CSF flow posterior to the spinal cord at the site of compression, indicating the lack of a detectable obstructing lesion, such as an arachnoid cyst. Computed tomography (CT) myelography showed homogeneous intrathecal contrast opacification on early and delayed images (Fig. 2A), anterior cord displacement, and severe posterior cord flattening (Fig. 2B), which are suggestive of an arachnoid web.

During T3-6 posterior laminectomies, intraoperative ultrasound revealed an extensive network of arachnoid membranes, bands, and webs tethering the spinal cord ventrally (Fig. 3). This arachnoid

ABBREVIATIONS CSF = cerebrospinal fluid; CT = computed tomography; MRI = magnetic resonance imaging

INCLUDE WHEN CITING Published May 17, 2021; DOI: 10.3171/CASE2142.

SUBMITTED January 20, 2021. ACCEPTED February 28, 2021.

(C) 2021 The authors, CC BY-NC-ND 4.0 (http://creativecommons.org/licenses/by-nc-nd/4.0/). 


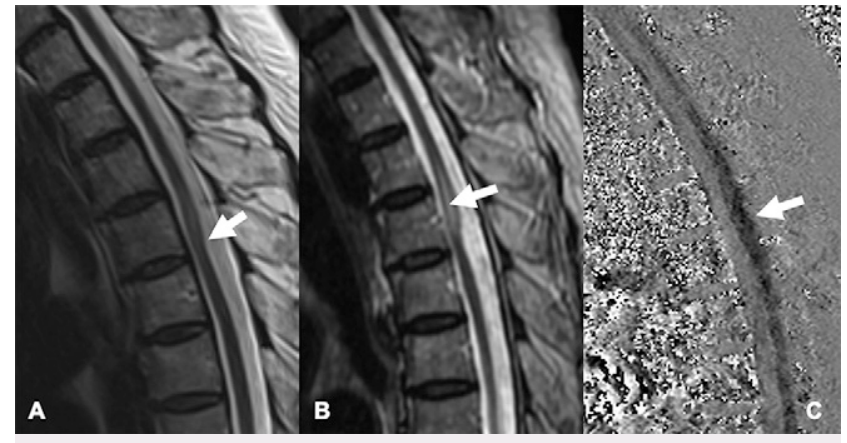

FIG. 1. MRI of the thoracic spine, sagittal views. A: T2-weighted imaging shows an indentation in the posterior aspect of the cord (arrow) consistent with the scalpel sign, which is highly suggestive of arachnoid web. B: Short-T1 inversion recovery imaging shows edema and focal cord enlargement cephalad to the indentation (arrow). C: Phase-contrast CSF imaging shows no detectable impediment to CSF flow posterior to the cord (arrow).

complex (Fig. 4) was microdissected and excised, resulting in immediate improvement of CSF flow, restoration of spinal cord position, and a significant reduction in spinal cord edema on postoperative MRI within a day (not shown). Significant improvement in lower extremity paresthesias and motor strength was noted within a few days of surgery. Follow-up at 6 weeks, 3 months, and 6 months showed gradual and eventually complete resolution of symptoms.

\section{Discussion}

\section{Observations}

The pathophysiology of spinal arachnoid webs remains unclear. Most of those uncommon and probably underreported lesions occur in the upper thoracic region. ${ }^{1-20}$ The lower cervical and upper thoracic posterior subarachnoid space contains numerous arachnoid strands and fibrils ${ }^{21}$ that coalesce to form a partition (the posterior

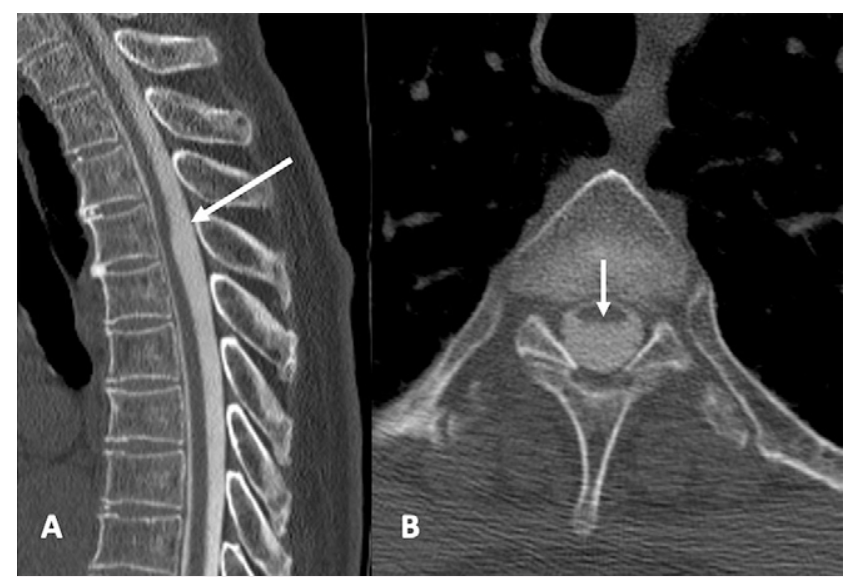

FIG. 2. CT myelography of the thoracic spine. A: Sagittal reconstruction clearly shows the scalpel sign (arrow). B: Axial imaging shows anterior cord displacement and severe flattening of the posterior aspect of the cord without evidence of a detectable mass (arrow).

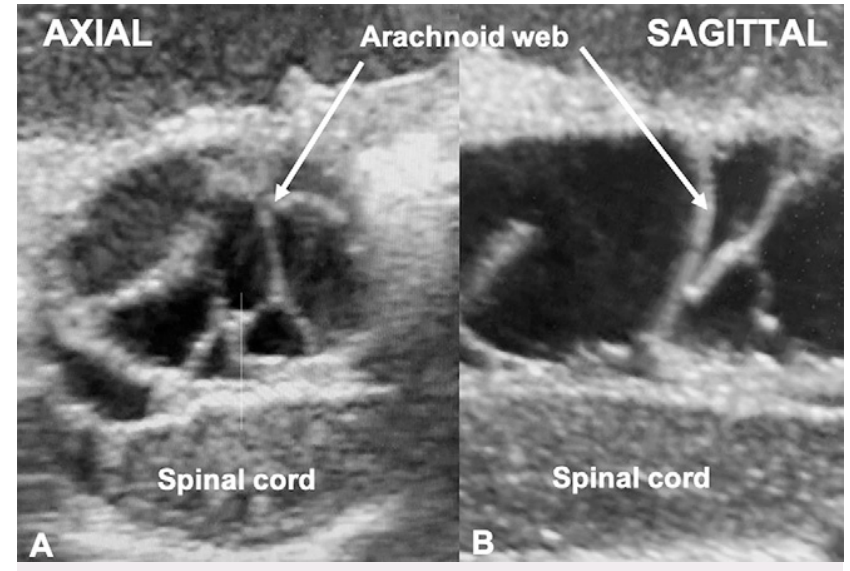

FIG. 3. Intraoperative ultrasound. A and B: There is significant upper thoracic cord anterior displacement by a complex network of arachnoid membranes (arrows). Internal echoes within CSF suggest impaired flow.

septum or septum posticum) and haphazardly arranged arachnoid trabeculae that have been dubbed "rogue strands" (Fig. 5). ${ }^{21} \mathrm{De}-$ scribed in 1842 by French physician François Magendie, ${ }^{22-24}$ the septum posticum is narrower at the posterior arachnoid membrane connection, wider at the base, and often septated (Fig. 5). In 1875, Swedish anatomists Axel Key and Gustaf Retzius ${ }^{25}$ described spinal subarachnoid membranous partitions in detail, including the dentate ligaments, arachnoid trabeculations, and septum posticum, which prolongs a focal thickening of the posterior arachnoid membrane known as the median raphe of Magendie (Fig. 5). ${ }^{21,26-28}$

The septum posticum's septations may be the site of origin for primary arachnoid cysts. ${ }^{2,22,29-32}$ Arachnoid webs may reflect ruptured or incompletely formed arachnoid cysts. ${ }^{5,22}$ Early 20th century monographs by German physicians Oppenheim and Krause ${ }^{33,34}$ described arachnoid trabeculations and webs as hydrops meningeus and arachnoid diverticulae and suggested an inflammatory or infectious origin, resulting in cyst formation, that was designated arachnitis serosa or cystica spinalis. ${ }^{22}$ However, those arachnoid structures were later found in many asymptomatic patients. ${ }^{35}$

Arachnoid webs and cysts may also derive from arachnoid recesses, ${ }^{36-38}$ in which the two arachnoid layers merge around the spinal nerve sheath origins (Fig. 5). Small lymphatic vessels, present around the arachnoid recesses, drain into satellite lymph nodes. ${ }^{39}$ The presence of activated macrophages and cellular debris within arachnoid

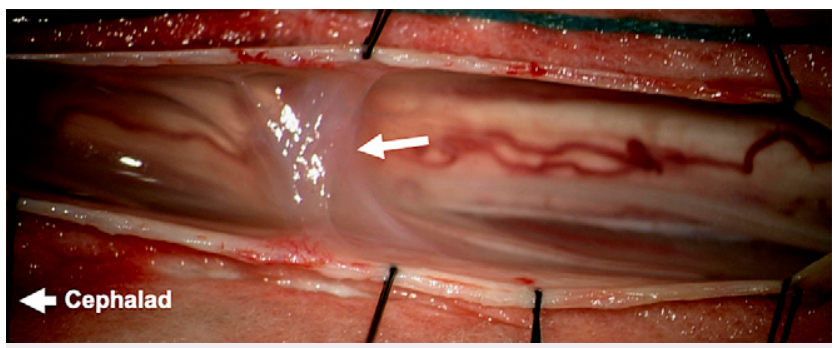

FIG. 4. Intraoperative photograph showing extensive dorsal arachnoid web across affected level (arrow). 


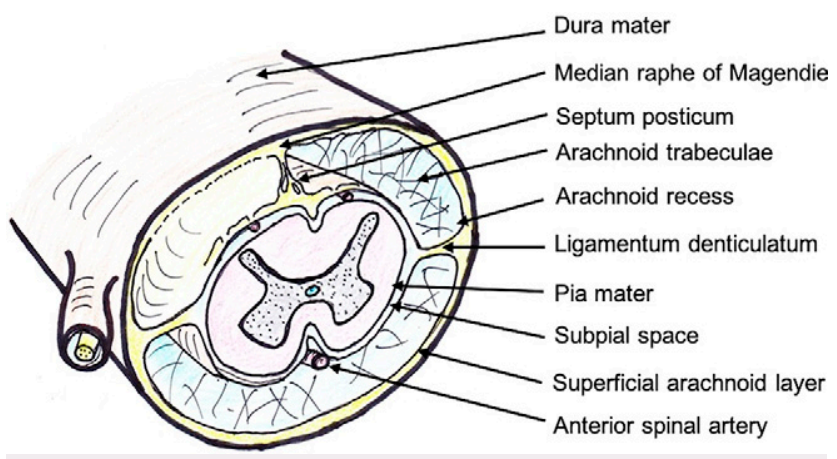

FIG. 5. Anatomical sketch showing intrathecal meningeal attachments of the spinal cord. The paired denticulate ligaments, the most robust and constant attachments, divide the anterior and posterior perimedullary spaces. The septum posticum is attached posteriorly to a focal thickening of the superficial arachnoid layer (the median raphe of Magendie) and anteriorly to the deep arachnoid layer. Note that the two arachnoid layers merge laterally to form the arachnoid recesses.

recesses suggests a role in immune defense of the central nervous system through local CSF molecular composition and physiology. ${ }^{36,39}$ Because most lymph nodes are located in the cervicothoracic area, inflammatory phenomena within the arachnoid recesses may trigger arachnoid proliferation around the septum posticum. ${ }^{26}$

\section{Lessons}

Current radiological diagnosis of arachnoid webs relies primarily on the scalpel sign on sagittal MRI or CT myelography. The sign consists of an indentation of the posterior spinal cord that resembles a surgical scapula with the blade pointing posteriorly (Figs. 1 and 2). Direct visualization of an arachnoid web on MRI has so far been reported only once. ${ }^{2}$ Although indirect evidence of CSF flow impairment may be obtained, that did not occur with our patient (Fig. 1). Other radiological signs include spinal cord edema and syrinx formation. Most reported cases were associated with syringomyelia, usually rostral but possibly caudal to the level of indentation. ${ }^{5}$ CSF flow impediment from posterior subarachnoid space obstruction, even if not demonstrated on CSF flow studies, as in our patient, may cause a pressure gradient (Venturi effect) from intramedullary passage of CSF through perivascular spaces during systole, resulting in cord edema (Figs. 1 and 2) that eventually culminates in syrinx formation. ${ }^{40}$ Other serious diagnostic considerations are spinal cord herniation and arachnoid cyst. In spinal cord herniation, a focal anterior spinal cord protrusion through a ventral dural defect ${ }^{41,42}$ may be difficult to identify on imaging. Arachnoid cysts have well-marginated walls, cause smooth scalloping on the spinal cord surface that is seen on MRI or CT myelography, ${ }^{43}$ and behave like space-occupying lesions on CSF flow studies.

Whether minimally symptomatic arachnoid webs should be operated on is currently unclear. Significant symptomatology includes neuropathic back pain and symptoms from compressive myelopathy, such as lower extremity weakness, paresthesias, and urinary and fecal incontinence. ${ }^{11}$ Surgical release of the thickened arachnoid membranes is the current standard of care. Although it has been suggested that symptomatic relief could be obtained by placing patients in the Trendelenburg position, ${ }^{24}$ symptomatology is now recognized to have a progressive rather than regressive course. ${ }^{44}$ More than $90 \%$ of patients experience rapid neurological recovery after resection, regardless of the duration of presenting symptoms. ${ }^{14-16}$

\section{References}

1. Mallucci CL, Stacey RJ, Miles JB, Williams B. Idiopathic syringomyelia and the importance of occult arachnoid webs, pouches and cysts. Br J Neurosurg. 1997;11(4):306-309.

2. Paramore CG. Dorsal arachnoid web with spinal cord compression: variant of an arachnoid cyst? Report of two cases. J Neurosurg. 2000;93(2 suppl):287-290.

3. Brodbelt AR, Stoodley MA. Syringomyelia and the arachnoid web. Acta Neurochir (Wien). 2003;145(8):707-711.

4. Sridharan A, Heilman CB. Transverse dorsal arachnoid web and syringomyelia: case report. Neurosurgery. 2009;65(1):E216-E217.

5. Reardon MA, Raghavan P, Carpenter-Bailey K, et al. Dorsal thoracic arachnoid web and the "scalpel sign": a distinct clinical-radiologic entity. AJNR Am J Neuroradiol. 2013;34(5):1104-1110.

6. Chang HS, Nagai A, Oya S, Matsui T. Dorsal spinal arachnoid web diagnosed with the quantitative measurement of cerebrospinal fluid flow on magnetic resonance imaging. J Neurosurg Spine. 2014;20(2): 227-233.

7. McCormick PC. Dorsal arachnoid web. Neurosurg Focus. 2014;37(suppl 2):Video 8.

8. Hakky MM, Justaniah Al, David C, et al. The neuroimaging spectrum of septum posticum derangement and associated thoracic myelopathy. J Neuroimaging. 2015;25(5):818-823.

9. Ruschel LG, Agnoletto GJ, Aurich LA, Vosgerau RP. Dorsal arachnoid web and scalpel sign: a diagnostic imaging entity. Turk Neurosurg. 2018;28(4):689-690.

10. Sayal PP, Zafar A, Carroll TA. Syringomyelia secondary to "occult" dorsal arachnoid webs: report of two cases with review of literature. J Craniovertebr Junction Spine. 2016;7(2):101-104.

11. Aiyer R, El-Sherif $Y$, Voutsinas L. Dorsal thoracic arachnoid web presenting as neuropathic pain: "scalpel" sign found on MRI. Neuroradiol J. 2016;29(5):393-395.

12. Hubbard ME, Hunt MA, Jones KE, Polly DW. Thoracic spinal cord impingement by an arachnoid web at the level of a hemivertebra: case report. J Neurosurg Spine. 2017;27(6):638-642.

13. Zhang D, Papavassiliou E. Spinal intradural arachnoid webs causing spinal cord compression with inconclusive preoperative imaging: a report of 3 cases and a review of the literature. World Neurosurg. 2017:99:251-258.

14. Vergara $P$, Barone DG. Minimally invasive excision of thoracic arachnoid web. World Neurosurg. 2018;109:e81-e87.

15. Ben Ali H, Hamilton P, Zygmunt S, Yakoub KM. Spinal arachnoid web: a review article. J Spine Surg. 2018;4(2):446-450.

16. Hirai T, Taniyama T, Yoshii T, et al. Clinical outcomes of surgical treatment for arachnoid web: a case series. Spine Surg Relat Res. 2018;3(1):43-48.

17. Kovai $P$, Sabharwal $P$, Singh AK. Dorsal arachnoid web: a missed entity. Neurol India. 2018;66(6):1839-1841.

18. Nisson PL, Hussain I, Härtl R, et al. Arachnoid web of the spine: a systematic literature review. J Neurosurg Spine. 2019;31(2): 155-297.

19. Wali AR, Birk HS, Martin J, et al. Neurosurgical management of a thoracic dorsal arachnoid web: case illustration. Cureus. 2019;11(6): e4945.

20. Aljuboori Z, Boakye M. Surgical release of a dorsal thoracic arachnoid web. World Neurosurg. 2020;143:289.

21. Parkinson D. Human spinal arachnoid septa, trabeculae, and "rogue strands." Am J Anat. 1991;192(4):498-509.

22. Perret G, Green D, Keller J. Diagnosis and treatment of intradural arachnoid cysts of the thoracic spine. Radiology. 1962;79:425-429. 
23. Magendie F. Recherches Physiologiques et Cliniques sur le Liquide Céphalo-Rachidien ou Cérébro-Spinal. Librairie Médicale de Méquignon-Marvis Fils; 1842.

24. Wyler AR, Loeser JD, Killien CF. Septum posticum cysts: an uncommon cause of chronic back pain. Pain. 1975;1(3):271-275.

25. Key E, Retzius MG. Studien in der Anatomie des Nervensystems. Arch Mikr Anat. 1875.

26. Vital JM, Cawley DT. Spinal Anatomy: Modern Concepts. SpringerVerlag; 2020.

27. Tubbs RS, Loukas M, Shoja MM, et al. François Magendie (1783-1855) and his contributions to the foundations of neuroscience and neurosurgery. J Neurosurg. 2008;108(5):1038-1042.

28. Di Chiro G, Timins EL. Supine myelography and the septum posticum. Radiology. 1974;111(2):319-327.

29. Holly LT, Batzdorf U. Syringomyelia associated with intradural arachnoid cysts. J Neurosurg Spine. 2006;5(2):111-116.

30. Takeuchi A, Miyamoto K, Sugiyama S, et al. Spinal arachnoid cysts associated with syringomyelia: report of two cases and a review of the literature. J Spinal Disord Tech. 2003;16(2):207-211.

31. Wang MY, Levi AD, Green BA. Intradural spinal arachnoid cysts in adults. Surg Neurol. 2003;60(1):49-56.

32. Petridis AK, Doukas A, Barth H, Mehdorn HM. Spinal cord compression caused by idiopathic intradural arachnoid cysts of the spine: review of the literature and illustrated case. Eur Spine J. 2010;19(suppl 2):S124-S129.

33. Krause F. Zur Kenntnis der Meningitis Serosa Spinalis. Berl Klin Wochenschr. 1906;43:827-832.

34. Oppenheim H. Beiträge zur Diagnostik und Therapie der Geschwülste im Bereich des Zentralen Nervensystems. S. Karger; 1907.

35. Teng P, Papatheodorou C. Spinal arachnoid diverticula. Br J Radiol. 1966;39(460):249-254.

36. Himango WA, Low FN. The fine structure of a lateral recess of the subarachnoid space in the rat. Anat Rec. 1971;171(1):1-19.

37. Nicholas DS, Weller RO. The fine anatomy of the human spinal meninges. A light and scanning electron microscopy study. J Neurosurg. 1988;69(2):276-282.
38. Joukal M, Klusáková I, Dubový P. Direct communication of the spinal subarachnoid space with the rat dorsal root ganglia. Ann Anat. 2016;205:9-15.

39. Bierley JM, Field EJ. The connexions of the spinal sub-arachnoid space with the lymphatic system. J Anat. 1948;82(part 3):153-166

40. Greitz D. Unraveling the riddle of syringomyelia. Neurosurg Rev. 2006;29(4):251-264.

41. Kwong Y, Jakanani G, Rao N, Fang CS. MRI findings in herniation of the spinal cord. J Radiol Case Rep. 2010;4(10):1-5.

42. Porrino J, Scherer KF, Gellhorn A, Avellino AM. Dural herniation of the spinal cord: a rare cause of myelopathy with unique imaging features. PM R. 2014;6(11):1063-1065.

43. Haber MD, Nguyen DD, Li S. Differentiation of idiopathic spinal cord herniation from CSF-isointense intraspinal extramedullary lesions displacing the cord. Radiographics. 2014;34(2):313-329.

44. Sharma P, Soin P, Elbanan M, Kochar PS. Understanding idiopathic spinal cord herniation-a comprehensive review of imaging and literature. J Clin Imaging Sci. 2019;9:22.

\section{Disclosures}

The authors report no conflict of interest concerning the materials or methods used in this study or the findings specified in this paper.

\section{Author Contributions}

Conception and design: Pham, Ebinu, Hacein-Bey. Acquisition of data: Pham, Ebinu. Analysis and interpretation of data: Pham, Ebinu, Karnati. Drafting the article: Pham, Ebinu, Karnati. Critically revising the article: Pham, Ebinu, Hacein-Bey. Reviewed submitted version of manuscript: Pham, Ebinu, Hacein-Bey. Approved the final version of the manuscript on behalf of all authors: Pham. Administrative/technical/material support: Pham, Karnati, Hacein-Bey. Study supervision: Pham.

\section{Correspondence}

Nancy Pham: University of California, Los Angeles, David Geffen School of Medicine, Los Angeles, CA. pham.nancy@gmail.com. 